\title{
The Effect of Growth at Elevated Temperatures on Some Heritable Properties of Staphylococcus aureus
}

\author{
By J. W. MAY, R. H. HOUGHTON AND C. J. PERRET \\ Department of Microbiology, University of Western Australia, \\ Medical School, Victoria Square, Perth, Western Australia
}

(Received 9 April 1964)

\begin{abstract}
SUMMARY
Populations of a predominantly tetracycline-resistant, penicillinasepositive strain of Staphylococcus aureus grown at $43-44^{\circ}$ gave rise to progressively increasing proportions of tetracycline-sensitive and penicillinasenegative cocci. The losses did not appear until after the elapse of a number of generations at the elevated temperature, and then apparently proceeded independently, tetracycline resistance being lost more rapidly than the ability to produce penicillinase. Tetracycline-sensitive and penicillinasenegative variants were extremely stable and the growth rates at $44^{\circ}$ of the parent strain and the tetracycline-sensitive variants were indistinguishable. Screening for numerous other ' marker' properties revealed no changes under the test conditions. The evidence suggests that tetracycline resistance and penicillinase-forming ability probably depend on the presence of two different plasmids in the cocci; that the replication-rates of the plasmids at elevated temperature are less than that of the cocci; and that the plasmids, once lost, are not spontaneously resynthesized nor, at least for that conferring tetracycline resistance, regained by infection. However, such a hypothesis raises the question of how equilibrium, particularly between the tetracycline-resistant and -sensitive cocci, is maintained in a population growing at $37^{\circ}$ and observed to change in one direction but never in the reverse direction.
\end{abstract}

\section{INTRODUCTION}

Strains of Staphylococcus aureus which owe their penicillin resistance to the production of penicillinase frequently give rise to penicillin-sensitive variants unable to produce the enzyme (Barber, 1949; Borowski, 1963); this change appears to be favoured by growth of the staphylococci at $44-45^{\circ}$ (Bondi, Kornblum \& de Saint Phalle, 1953; Fairbrother, Parker \& Eaton, 1954). In order to isolate penicillinase-negative variants of penicillinase-positive strains of $S$. aureus for comparison of metabolic properties, a number of suitable strains was therefore

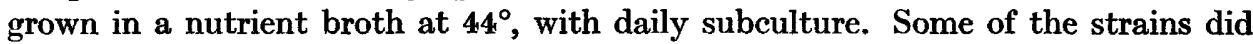
indeed produce penicillinase-negative variants as time elapsed, and in some instances the change occurred more rapidly than reported by Fairbrother et al. (1954). In addition, one strain which initially was also tetracycline-resistant gave rise to apparently 'pure' tetracycline-sensitive populations. The investigations reported here suggest that in this strain of $S$. aureus, penicillinase production and tetracycline resistance, alone among a number of properties tested, are independently determined by the presence of heat-sensitive plasmids.

Vol. 37, No. 1 was issued 7 December 1964 


\section{METHODS}

Organism. Staphylococcus aureus strain E 169, isolated from a clinical source in Western Australia, was used in this investigation. Following three successive single colony pickings, a streak sample was dried in ampoules by the method of Annear (1962); a new ampoule was opened to provide the inoculum for each experiment. Cultures of $S$. aureus E 169 produce penicillinase (phenotypically represented by Penase $^{+}$), and are resistant to penicillin $\left(\mathrm{Pen}^{\mathrm{R}}\right)$ and tetracycline $\left(\right.$ Tet $\left.^{\mathbb{R}}\right)$. The criteria used for designating the strain Pen $^{\mathbb{R}}$ and Tet $^{\mathbb{R}}$ were the high survival rates obtained when cultures were plated on medium containing either penicillin $\mathrm{G} 1$ i.u. $/ \mathrm{ml}$. or tetracycline $3 \mu \mathrm{g} . / \mathrm{ml}$. The phage type of the strain is $52 / 52 \mathrm{~A} / 80 / 81 / \mathrm{KS} 6$.

Growth media. The initial liquid medium was a nutrient broth (NB-1) consisting of 'Oxoid' Nutrient Broth granules, 13 g.; $\mathrm{KH}_{2} \mathrm{PO}_{4}, 1.5 \mathrm{~g}$.; $\mathrm{K}_{2} \mathrm{HPO}_{4}, 3.5 \mathrm{~g}$.; distilled water to $1000 \mathrm{ml}$; autoclaved at $115^{\circ}$ for $10 \mathrm{~min}$. A $20 \%$ solution of glucose was added immediately before use to give a final concentration of $0.1 \%$. Subsequently, a meat infusion broth (MIB) prepared in the manner described in Mackie \& McCartney's Handbook (1960) was used. Nutrient agar (NA-1) and meat infusion agar (MIA) were prepared by the addition of $1 \%$ 'Oxoid' Ionagar to NB-1 and MIB respectively.

Growth procedure. The bacteria were grown overnight in the liquid medium as a static batch culture at $25^{\circ}$. The following morning $20 \mathrm{ml}$. of the medium in a plugged $100 \mathrm{ml}$. conical flask was inoculated from the overnight culture with organisms equivalent to about $0.05 \mathrm{mg}$. bacterial dry wt. $/ \mathrm{ml}$. The culture was then incubated at $37^{\circ}$ on a hot-room shaker (Kantorowicz, 1951): the population density was maintained as nearly as practicable within the range equivalent to $0 \cdot 05-0 \cdot 10 \mathrm{mg}$. bacterial dry wt./ml. by withdrawal of accurate $10 \mathrm{ml}$. samples of the culture at suitable intervals, followed by the immediate replacement with $10 \mathrm{ml}$. of prewarmed medium. The withdrawn culture samples were killed by the addition of $1 \mathrm{ml}$. formalin and their extinction measured.

When the extinction measurements showed that the growth rate at $37^{\circ}$ had remained constant for three successive doublings, $10 \mathrm{ml}$. of the culture was rapidly added to $10 \mathrm{ml}$. of pre-warmed medium contained in a plugged conical flask attached to a shaker in a thermostatically controlled water bath at the elevated temperature (usually within the range $43-44^{\circ}$ ) and the shaker set at 100 oscillations/min. with an $8 \mathrm{~cm}$. throw. In the initial experiments, the growth temperature was taken as that registered by a mercury thermometer immersed in the bath. When it became obvious that an accurate knowledge of growth temperature was of critical importance, it was measured by means of a plastic-covered thermocouple entering through a side-arm in the growth flask and immersed in the culture. The thermocouple, type F 6, was used with an 'Ellab Universal Precision Thermometer', model TE. 3 (Electrolaboratoreit, Copenhagen, Denmark), calibrated against an N.P.L.-certificated standard thermometer. Culture temperatures were found to be constant within $\pm 0.05^{\circ}$ throughout an experiment.

The repeated doubling-dilution regime was usually continued at the elevated temperature for about 9 doublings. Of the $10 \mathrm{ml}$. of culture withdrawn at each dilution stage, $1 \mathrm{ml}$. was added to $9 \mathrm{ml}$. of $0.1 \%$ peptone water, further diluted in 
peptone water, and then plated-out on medium NA-1 or MIA for single-colony pickings; the remaining $9 \mathrm{ml}$. was formolized and used for extinction measurement.

The plates were incubated at $37^{\circ}$ overnight, and 100 or more clearly-isolated colonies picked-off and replicated on a set of plates of 'marker' media in order to detect any changes in the chosen properties. In most of the experiments, the only properties studied were tetracycline susceptibility and penicillinase production. Results of the marker-medium tests were read after further overnight incubation at $\mathbf{3 7 ^ { \circ }}$.

Optical extinction measurements. The extinction of bacterial suspensions was measured in a Hilger 'Spekker' Absorptiometer (Hilger \& Watts Ltd., Camden Way, London, N.W. 1, England) with the large $1 \mathrm{~cm}$. light-path cells, the Neutral Grey $\mathrm{H} 508$ filters and the growth medium as blank. Extinction readings were converted to mg. bacterial dry wt./ml. by means of a calibration curve, and then multiplied by the appropriate dilution factor to give a 'cumulative' growth curve.

Cell-wall stain. An agar plate was flooded with the formolized bacterial culture and the excess removed. After drying-in, impression films were prepared by attaching agar blocks to coverslips and immersing overnight in $70 \%(v / v)$ ethanol in water containing $1 \%(\mathrm{v} / \mathrm{v})$ acetic acid. The films were stained by the method of Bisset \& Hale (1953) and then mounted over medium type ABP (Valnor Corp., Brooklyn 1, N.Y., U.S.A.). Cocci with deeply stained cross-walls were scored as two cells.

Screening procedure. Colonies to be tested for altered characteristics were picked from the primary plates and suspended in sterile distilled water contained in the wells of a multipoint inocular tray (May \& Houghton, 1964). Selected marker media were then serially inoculated with these suspensions.

Antibiotic marker media. These media consisted of medium NA-1 containing antibiotics at the following concentrations : 5 i.u. penicillin $\mathrm{G} / \mathrm{ml}$.; or $10 \mu \mathrm{g}$. tetracycline/ $\mathrm{ml}$.; or 100 or $1000 \mu \mathrm{g}$. streptomycin/ml.; or 2 or $20 \mu \mathrm{g}$. chloramphenicol $/ \mathrm{ml}$.; or $0 \cdot 3 \mu \mathrm{g}$. erythromycin $/ \mathrm{ml}$.; or $1000 \mu \mathrm{g}$. sulphadiazine $/ \mathrm{ml}$. Selection of the concentrations was based on the known susceptibility spectrum of Staphylococcus aureus E 169; the aim was to detect significant increases or decreases in susceptibility.

Fermentation marker media. Media for the detection of acid production from carbohydrates consisted of medium NA-2 (medium NA-1 with the glucose and phosphates omitted), into each $100 \mathrm{ml}$. of the molten cooled medium was mixed $5 \mathrm{ml}$. of an indicator solution (containing bromcresol purple $0.1 \mathrm{~g}$., $0.05 \mathrm{~N}-\mathrm{NaOH}$ 3.7 ml., distilled water to $250 \mathrm{ml}$.) and $5 \mathrm{ml}$. of a $20 \%$ solution of the appropriate carbohydrate. Indicator and carbohydrate solutions had been previously autoclaved separately at $115^{\circ}$ for $10 \mathrm{~min}$. The carbohydrates used were lactose, glucose, mannitol, maltose and sucrose.

Auxotrophic marker medium. A medium designed to detect any increased nutritional requirements consisted of $1 \%$ 'Oxoid' Ionagar containing three solutions of salts (A, B and C; compositions described below) and the following nutrients in the stated amounts/ml.: glucose, $2 \mathrm{mg}$; glutamic acid, $1 \mathrm{mg}$. (neutralized with $\mathrm{N}$ $\mathrm{NaOH}$ ); histidine, glycine, arginine, proline and pantothenic acid, $10 \mu \mathrm{g}$.; thiamine and nicotinic acid, $1 \mu \mathrm{g}$. Solutions $\mathrm{A}, \mathrm{B}$ and $\mathrm{C}$ each consisted of $100 \mathrm{ml}$. of distilled water in which were dissolved the following compounds: (A) $\mathrm{K}_{2} \mathrm{HPO}_{4}, 70 \mathrm{~g}$.; $\mathrm{KH}_{2} \mathrm{PO}_{4}, 30$ g.; (B) $\mathrm{MgSO}_{4} .7 \mathrm{H}_{2} \mathrm{O}, 1 \mathrm{~g}$.; $\mathrm{NaCl}$ and $\mathrm{MnSO}_{4} .4 \mathrm{H}_{2} \mathrm{O}, 0 \cdot 2 \mathrm{~g}$; $(\mathrm{C})\left(\mathrm{NH}_{4}\right)_{2}{ }^{-}$ 
$\mathrm{SO}_{4} \mathrm{FeSO}_{4} \cdot \mathrm{H}_{2} \mathrm{O}$ and citric acid, 0.15 g. All nutrient and salt solutions were autoclaved separately at $115^{\circ}$ for $10 \mathrm{~min}$. and added to the molten cooled agar solution. Solutions A, B and C were incorporated at the respective rates of $0.5 \mathrm{ml} ., 0.5 \mathrm{ml}$., and $0.05 \mathrm{ml} . / 100 \mathrm{ml}$. medium.

Haemolysin marker medium. Into $100 \mathrm{ml}$. of molten cooled medium NA-1 were mixed $7 \mathrm{ml}$. of a sterile suspension of sheep red cells, prepared by washing citrated blood three times with saline and resuspending to its original volume. Each plate contained $10 \mathrm{ml}$. medium; plates were incubated in an atmosphere of $10 \% \mathrm{CO}_{2}$ and $90 \% \mathrm{O}_{2}$. Under these conditions, growth of Staphylococcus aureus E 169 was surrounded by a zone of complete haemolysis. When intersected by a zone of $\beta$-haemolysis, this clear zone was completely suppressed, indicating that $S$. aureus $\mathrm{E} 169$ produces $\alpha$-haemolysin (Elek \& Levy, 1954).

Phosphatase marker medium. Phosphatase was detected by the procedure of Barber \& Kuper (1951), except that medium NA-2 was used as the base agar.

Coagulase marker medium. Into $80 \mathrm{ml}$. of molten NA-1 medium at $50^{\circ}$ were mixed $20 \mathrm{ml}$. of fresh sterile human plasma, and soya-bean trypsin inhibitor (L. Light and Co. Ltd., Colnbrook, England) to a final concentration of $5 \mu \mathrm{g} . / \mathrm{ml}$. (Klemperer \& Haughton, 1957). Correctly prepared plates were quite transparent when set.

Staphylokinase marker medium. Into $80 \mathrm{ml}$. of molten NA-1 medium at $50^{\circ}$ were mixed $20 \mathrm{ml}$. of fresh sterile human plasma; the mixture was then heated at $56^{\circ}$ for $30 \mathrm{~min}$. and the plates poured. Correctly prepared plates showed an even haziness. On this medium, colonies of Staphylococcus aureus E 169 were surrounded by zones of punctate lysis, i.e. Muller's phenomenon, indicating the production of staphylokinase (Hutchison, 1962).

Penicillinase marker medium. Medium and detection procedure were as described by Foley \& Perret (1962).

Phage typing. Phage typing was carried out by the procedures laid down by Blair \& Williams (1961).

Lysogenicity. The presence of free phage in filtrates of actively growing cultures (population density equivalent to about $0.1 \mathrm{mg}$. dry wt./ml.) was determined by the agar-layer method of Gratia (Adams, 1959).

\section{RESULTS}

\section{Growth and loss of antibiotic resistance in nutrient broth}

Although Staphylococcus aureus $\mathrm{E} 169$ grew in tubes of nutrient broth (medium NB-1) immersed in a water bath regulated at about $44^{\circ}$, little or no growth was obtained when the temperature of the culture, instead of that of the bath, was accurately controlled at $44^{\circ}$. Figure 1 shows that, following transfer from $37^{\circ}$ to $44^{\circ}$, the first two doublings were achieved in about $22 \mathrm{~min}$. each; this corresponds to a shortening of the doubling time at $37^{\circ}$ by $4 \mathrm{~min}$. Thereafter, the growth rate rapidly decreased; the culture failed to complete the third doubling, and began to lyse between 105 and $180 \mathrm{~min}$. after the temperature shift. The inability of $S$. aureus E 169 to grow at $44^{\circ}$ necessitated the lowering of the growth-temperature to $43^{\circ}$.

The nature of the growth and loss phenomena when Staphylococcus aureus $\mathbf{E} 169$ was grown in medium NB-1 at $43^{\circ}$ is shown in Figs. 2 and 3. Following transfer to the higher temperature, the first two doublings of the culture occupied about $21 \mathrm{~min}$. 


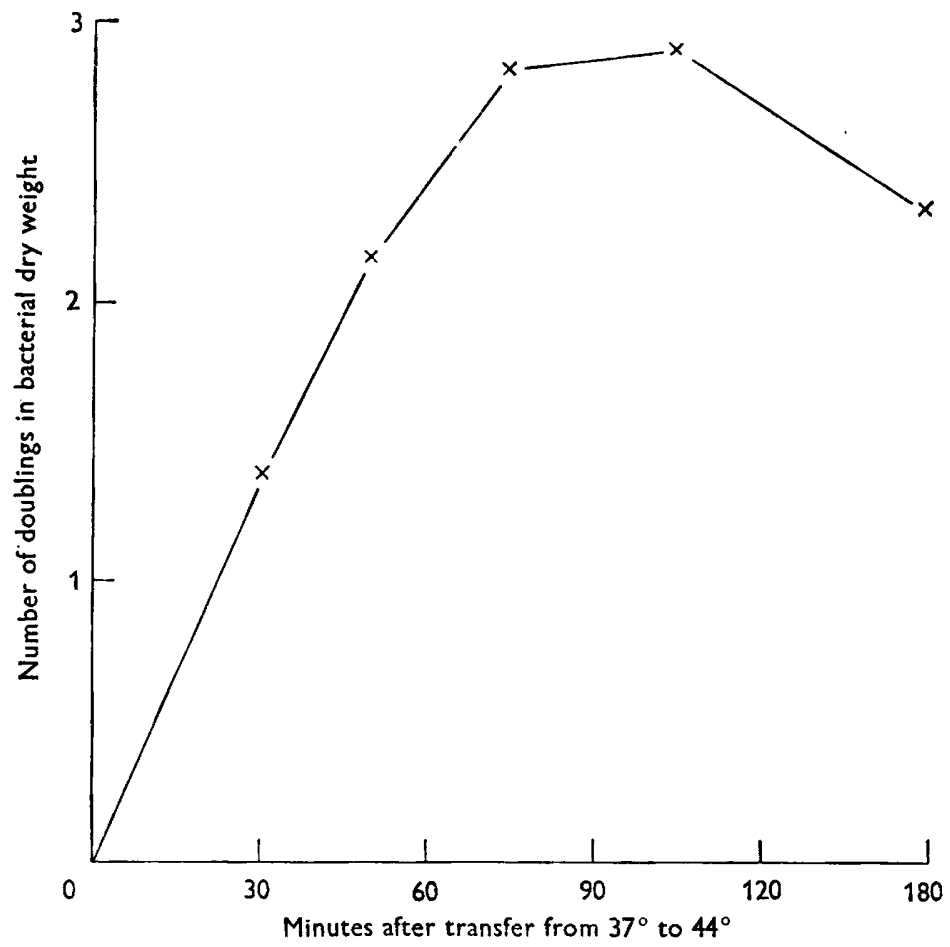

Fig. 1. Cumulative growth curve of Staphylococcus aureus E 169 in medium NB-1 following transfer from $37^{\circ}$ to $44^{\circ}$.

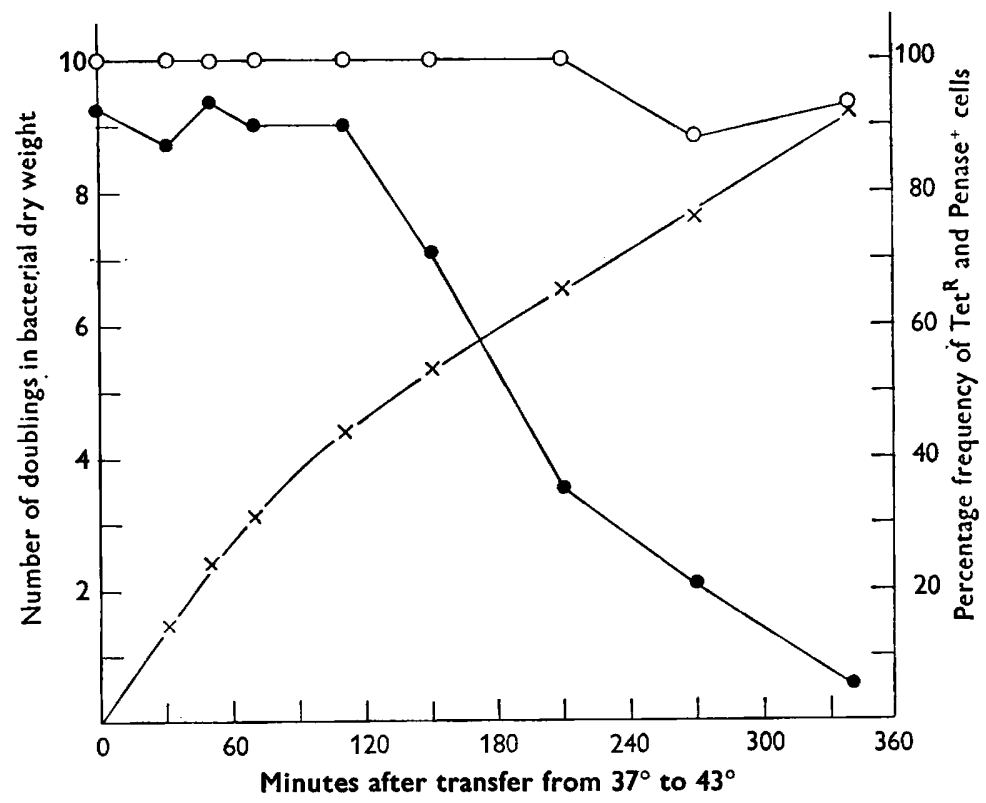

Fig. 2. Cumulative growth curve $(x-x)$ and frequency of $\operatorname{Tet}^{\mathrm{R}}$ cocci $(-0)$ and of Penase $^{+}$cocci $\left(\mathrm{O}^{-} \mathrm{O}\right)$ of Staphylococcus aureus $\mathrm{E} 169$ in medium NB-1 following transfer from $37^{\circ}$ to $43^{\circ}$. 
each. Between the second and fifth doublings, the growth rate slowly declined producing an inflexion in the growth curve; thereafter the doubling time of the culture remained constant at about $50 \mathrm{~min}$. Up to about the fifth doubling, the proportion of Tet $^{\mathrm{s}}$ and Penase- cocci remained at their $37^{\circ}$ values, i.e. about 10 and $1 \%$, respectively. Thereafter, the proportion of $\mathrm{Tet}^{\mathrm{s}}$ cocci increased so rapidly that the Tet $^{\mathbb{R}}$ cocci were 'diluted-out' with a 'halving-time' almost equal to the doubling-

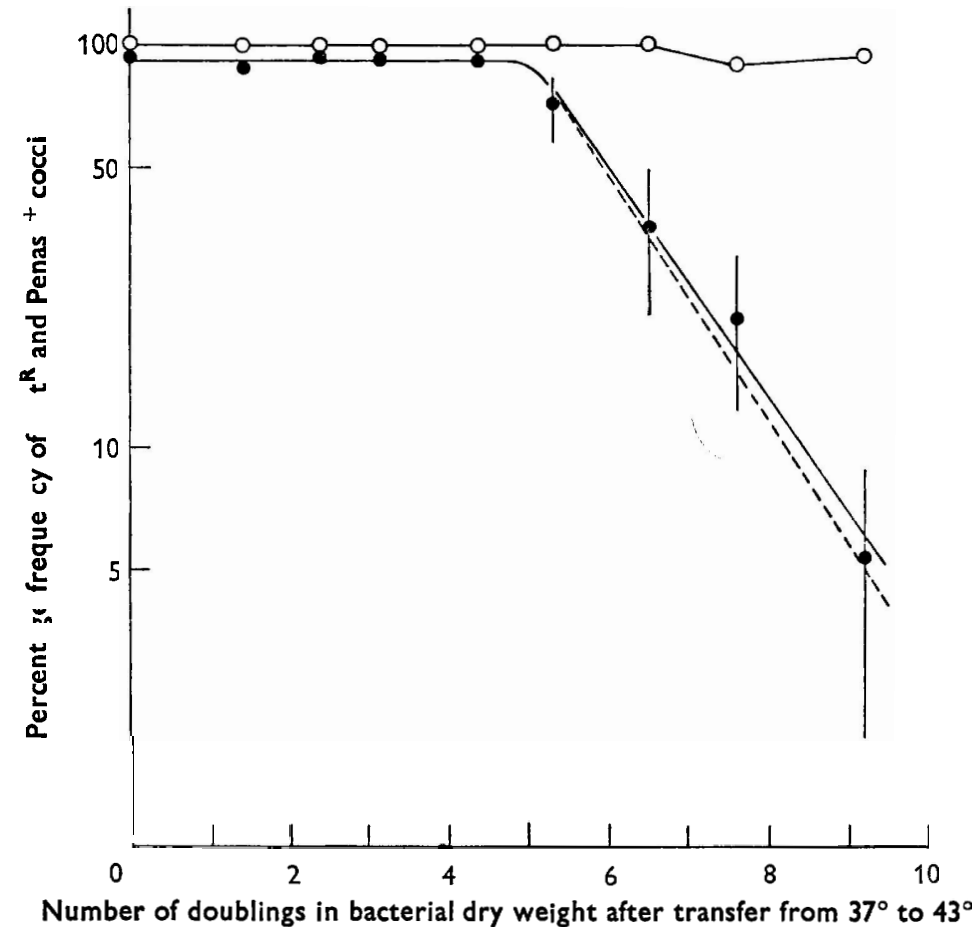

Fig. 3. Relationship between the number of doublings in bacterial dry weight completed by Staphylococcus aureus $\mathrm{E} 169$ in medium NB-1 following transfer from $37^{\circ}$ to $43^{\circ}$, and the frequency of Tet $^{\mathrm{R}}$ cocci $(-)$ ) and of Penase ${ }^{+}$cocci $(\mathrm{O}-\mathrm{O})$. The broken line corresponds to what would be the expected frequency of hypothetical 'passive' particles, i.e. ones that are neither replicated nor destroyed during growth. The vertical lines indicate $95 \%$ confidence limits.

time of the culture (the number of halvings in percentage frequency of Tet $^{\mathrm{R}}$ cocci/ doubling of bacterial mass was $\mathbf{0 . 9 4}$ ). Starting a little later, Penase ${ }^{+}$cocci were also 'diluted-out', but at a much slower rate than the $\mathrm{Tet}^{\mathrm{R}}$ cocci.

When approximately $10^{11}$ organisms of $\mathrm{Tet}^{\mathrm{S}}$ variants and $10^{9}$ organisms of Penase $^{-}$variants, isolated at both $37^{\circ}$ and $43^{\circ}$, were plated on to medium NA-1 containing either tetracycline $3 \mu \mathrm{g} . / \mathrm{ml}$. or penicillin $\mathbf{G ~} 1$ i.u. $/ \mathrm{ml}$., no spontaneous revertant colonies were observed. The Tet $^{\mathrm{g}}$ and Penase $^{-}$variants were therefore extremely stable.

\section{Growth and loss of antibiotic resistance in meat infusion broth}

At this stage, the initial batch of 'Oxoid' Nutrient Broth became nearly exhausted, and it was found that the new batch was useless for our purposes. At $43^{\circ}$ media 
prepared from the new batch gave such extremely granular cultures that extinction measurements were impossible. Tests of other readily available media revealed that our meat infusion broth (MIB) gave fully dispersed cultures even at $44^{\circ}$, the temperature which was originally used by Fairbrother et al. (1954). MIB and a growth temperature of $44^{\circ}$ were therefore adopted for all subsequent experiments; typical results are shown in Fig. 4. The decline in the proportion of Tet $^{\mathrm{R}}$ and Penase ${ }^{+}$

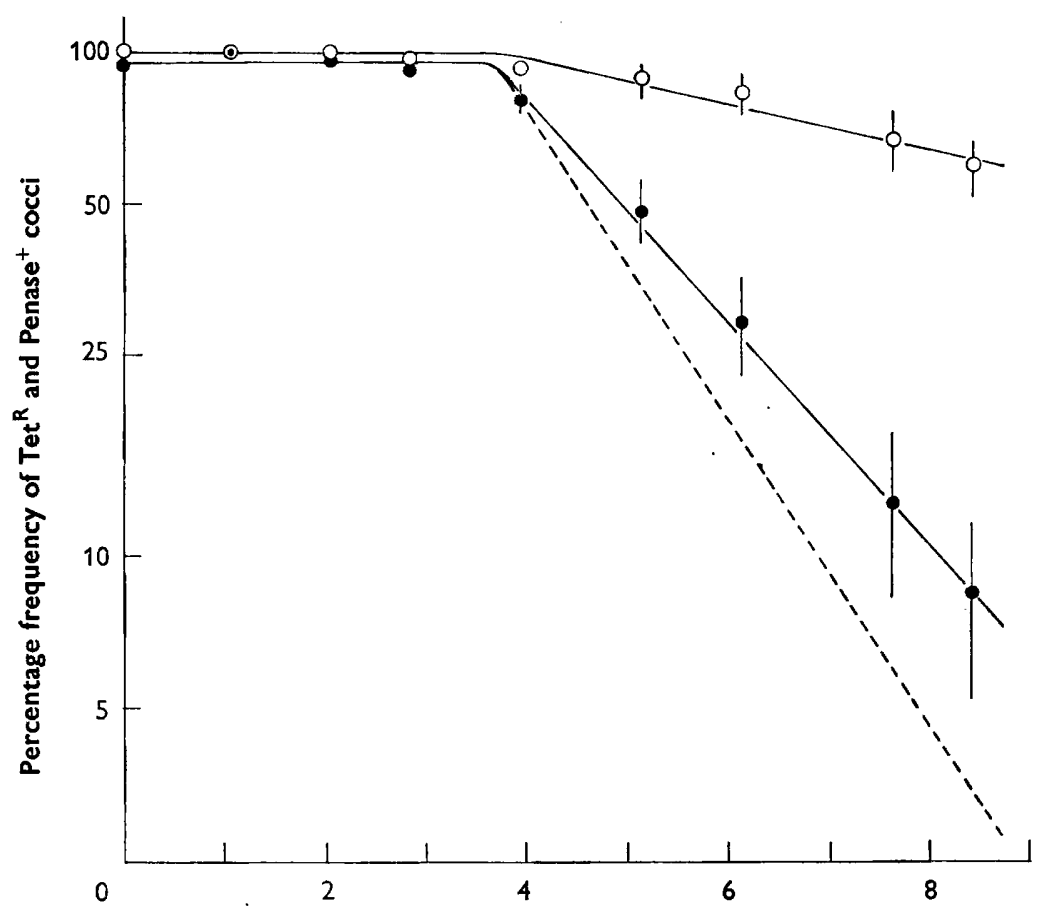

Number of doublings in bacterial dry weight after transfer from $37^{\circ}$ to $44^{\circ}$

Fig. 4. Relationship between the number of doublings in bacterial dry weight completed by Staphylococcus aureus $\mathrm{E} 169$ in MIB following transfer from $37^{\circ}$ to $44^{\circ}$, and the frequency of $\mathrm{Tet}^{\mathrm{R}}$ cocci $(-\mathrm{O})$ and of Penase ${ }^{+}$cocci $(\mathrm{O}-\mathrm{O})$. The broken line corresponds to what would be the expected frequency of hypothetical 'passive' particles, i.e. ones that are neither replicated nor destroyed during growth. The vertical lines indicate $95 \%$ confidence limits.

cocci started between the third and fourth doublings, which was earlier than in medium NB-1 at $43^{\circ}$, and by the fifth doubling the proportion of Tet ${ }^{\mathrm{R}}$ cocci had fallen to approximately $50 \%$. However, the 'dilution-out', at least for Tet ${ }^{\mathrm{R}}$ cocci, $^{2}$ proceeded at a slower rate than in medium NB-1. Thus, between approximately the fourth and eighth doublings, the number of halvings in percentage frequency of Tet $^{\mathrm{R}}$ cocci/doubling of bacterial mass, was $0 \cdot 73$. Examination of bacteria stained to reveal cell walls showed that the mean number of cells per clump (excluding the tail of the frequency distribution above the ninth decile) was approximately 2 , with median and mode of 2 , prior to transfer from $37^{\circ}$ to $44^{\circ}$; and was approximately 4 , with median and mode of 4 , after 5 or more doublings at $44^{\circ}$.

Since one possible explanation of the observed population changes was that the parental type virtually stopped reproducing (while remaining viable) and was 


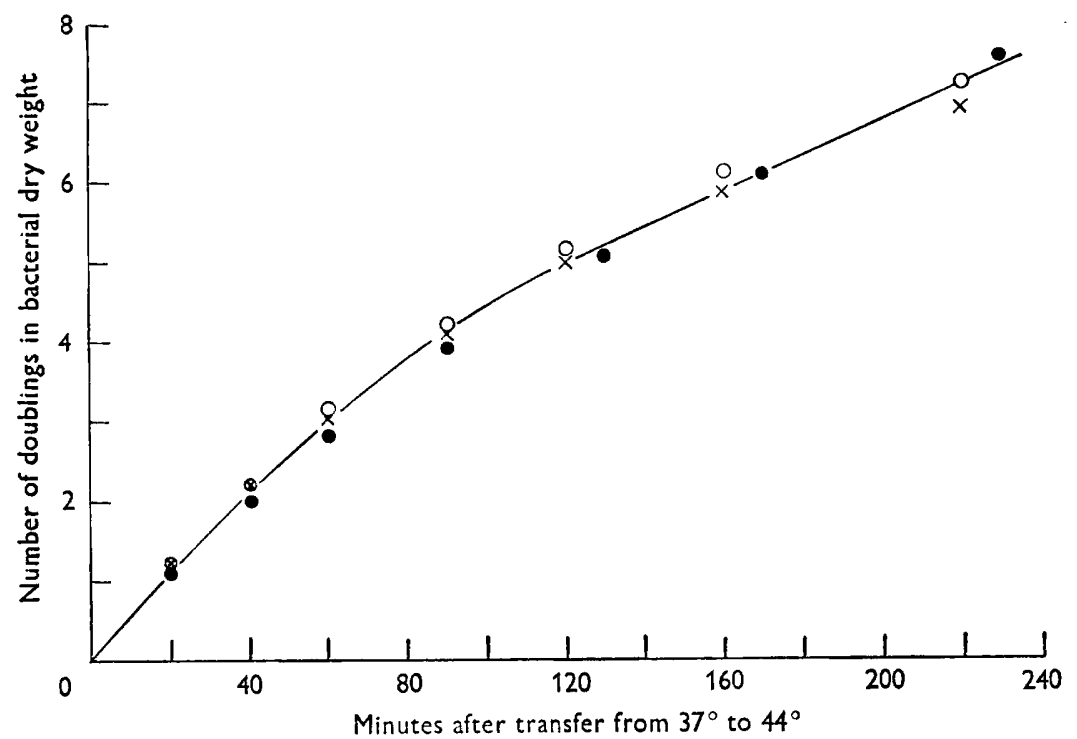

Fig. 5. Cumulative growth curves in MIB following transfer from $37^{\circ}$ to $44^{\circ}$ of Staphylococcus aureus $\mathrm{E} 169(-))$, and of $\mathrm{Tet}^{\mathrm{s}}$ variants isolated from cultures grown at either $37^{\circ}(O-O)$ or at $44^{\circ}(x-x)$.

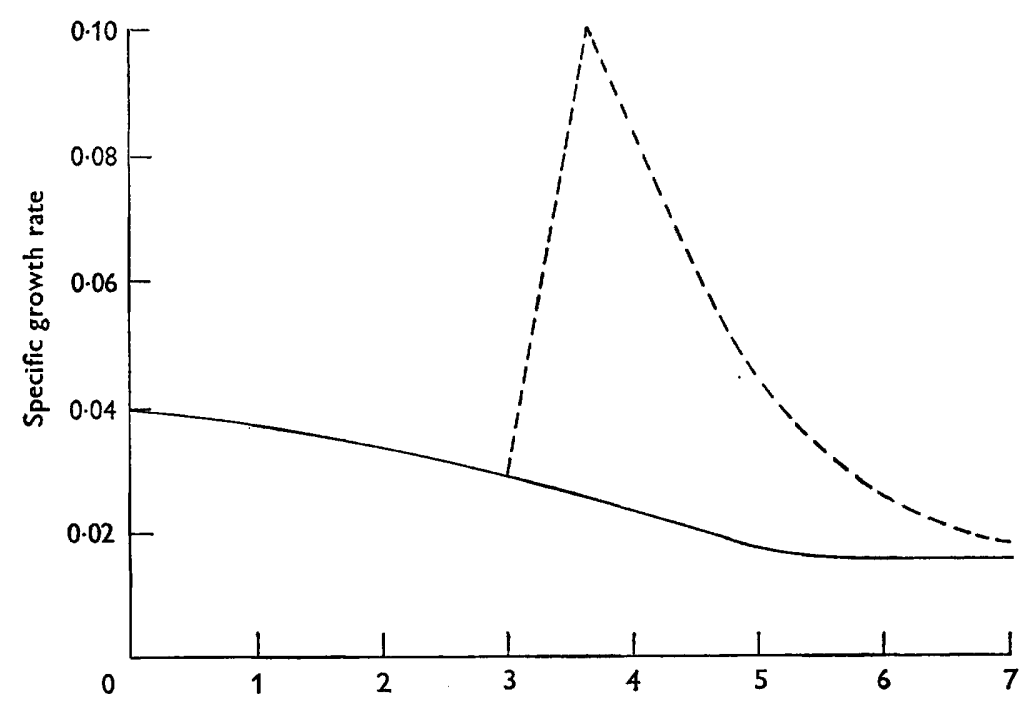

Number of doublings in bacterial dry weight after transfer from $37^{\circ}$ to $44^{\circ}$

Fig. 6. The relationship between specific growth rate and the number of doublings in bacterial dry weight completed by Staphylococcus aureus $\mathrm{E} 169$ in MIB following transfer from $37^{\circ}$ to $44^{\circ}$. The unbroken line shows the specific growth rate of the whole culture taken from Fig. 5. The broken line indicates the specific rate at which the Tet $^{\mathrm{s}}$ variants would need to grow in order to account for the observed decrease in percentage frequency of Tet $^{\mathrm{R}}$ cocci shown in Fig. 4. 
overgrown by the variants, the growth curves at $44^{\circ}$ of $\mathrm{Tet}^{\mathrm{s}}$ variants isolated at both $37^{\circ}$ and $44^{\circ}$ were compared with that of the original Staphylococcus aureus E 169; Fig. 5 shows that the growth curves of the three strains were in fact almost identical. Fig. 6 shows the specific growth rates of the three strains (calculated from the fitted curve in Fig. 5), together with the specific growth rate which would be needed if the Tet ${ }^{\mathrm{s}}$ variants were to overgrow the Tet $^{\mathrm{R}}$ cocci at a rate which would explain the observed proportional diminution of the latter revealed in Fig. 4. It seems clear from Fig. 6 that the observed changes in the Tet $^{\mathrm{R}}:$ Tet $^{\mathrm{s}}$ ratio could not possibly be caused by differences in the growth rates of the two types.

Table 1. Effect of growth in MIB at $44^{\circ}$ upon various marker properties of Staphylococcus aureus $\mathrm{E} 169$

\begin{tabular}{|c|c|c|}
\hline \multirow[b]{2}{*}{ Property } & \multicolumn{2}{|c|}{$\begin{array}{l}\text { Percentage frequency of cocci } \\
\text { positive after } n \text { doublings in } \\
\text { bacterial dry weight at } 44^{\circ}\end{array}$} \\
\hline & $n=0$ & $n=\mathbf{9} \cdot \mathbf{3}$ \\
\hline \multicolumn{3}{|l|}{ Growth on } \\
\hline Penicillin (5 i.u. $/ \mathrm{ml}$.) & 100 & 58 \\
\hline Tetracycline (10 $\mu \mathrm{g} . / \mathrm{ml})$. & 98 & $\mathbf{1} \cdot \mathbf{3}$ \\
\hline Streptomycin $(100 \mu \mathrm{g} . / \mathrm{ml})$. & 100 & 100 \\
\hline Streptomycin $(1000 \mu \mathrm{g} . / \mathrm{ml})$. & $\mathbf{0}$ & $\mathbf{0}$ \\
\hline Chloramphenicol (2 $\mu \mathrm{g} . / \mathrm{ml})$. & 100 & 100 \\
\hline Chloramphenicol (20 $\mu \mathrm{g} . / \mathrm{mi})$. & $\mathbf{0}$ & $\mathbf{0}$ \\
\hline Erythromycin (0.3 $\mu \mathrm{g} . / \mathrm{ml})$. & $\mathbf{0}$ & $\mathbf{0}$ \\
\hline Sulphadiazine $(1000 \mu \mathrm{g} . / \mathrm{ml})$. & 100 & 100 \\
\hline Auxotrophic medium & 100 & 100 \\
\hline \multicolumn{3}{|l|}{ Production of } \\
\hline Penicillinase & 100 & $\mathbf{5 8}$ \\
\hline $\left.\begin{array}{c}\text { Coagulase, phosphatase, } \\
\text { staphylokinase, haemolysin }\end{array}\right\}$ & 100 & 100 \\
\hline \multicolumn{3}{|l|}{ Fermentation of } \\
\hline $\begin{array}{l}\text { Lactose, glucose, mannitol, } \\
\text { maltose, sucrose }\end{array}$ & 100 & 100 \\
\hline
\end{tabular}

Effect of growth at elevated temperature on other properties. To discover whether the 'instability' of tetracycline resistance and penicillinase-forming ability of Staphylococcus aureus $\mathrm{E} 169$ was shared by other properties, a doubling-dilution growth-run, lasting for about nine doublings in MIB at $44^{\circ}$, was accompanied by replication of colonies on a wide range of 'marker' media. Table 1 shows the percentage composition of the bacterial population with respect to the various properties at the start and finish of the experiment. It can be seen that tetracycline resistance, production of penicillinase and penicillin resistance were the only properties which showed any change within the range of sensitivity allowed by the limited number of colonies tested. All marker media gave unequivocal results, except the lactose fermentation medium. S. aureus E 169 is a slow or weak lactose fermenter; nevertheless, it did appear that some of the colonies from the final sample had produced even less acid than usual. But no difference between these colonies and normal $S$. aureus $\mathbf{E} 169$ was detected when a comparison was made in the standard lactose-peptone water. The culture was therefore recorded as showing no change with respect to lactose fermentation. 
Staphylococcus aureus $\mathrm{E} 169$ is lysogenic, releasing one or more phages active on S. aureus NCTC 9789 (the propagating strain for staphylococcal phage 80). However, loss of either tetracycline resistance or penicillinase-forming ability was not associated with loss of prophage since none of three different heat-induced variants (Tet $^{\mathrm{R}}$ Penase- Tet $^{\mathrm{s}}$ Penase ${ }^{+}$; and Tet $^{\mathrm{s}}$ Penase $^{-}$) showed any alteration in phage type and all were immune to phage released by the parental type.

Effect of acriflavine treatment and ultraviolet irradiation upon the frequency of Tet ${ }^{s}$ and Penase- variants. Following growth in MIB containing $0 \cdot 1 \mathrm{mg}$. acriflavine $/ \mathrm{ml}$., of 200 colonies tested $6 \%$ were Tet $^{\mathrm{s}}$ and $2 \%$ were Penase ${ }^{-}$; similarly, when about $5 \times 10^{8}$ cocci were subjected to ultraviolet irradiation, of the approximately 200 colonies surviving, $5 \%$ were Tet $^{\mathrm{s}}$ and $1 \%$ were Penase- ${ }^{-}$. Therefore neither of these two agents significantly affects the frequency of $\mathrm{Tet}^{\mathrm{s}}$ or Penase- variants in populations of Staphylococcus aureus $\mathrm{E} 169$.

Table 2. Frequency of tetracycline-sensitive variants of Staphylococcus aureus $\mathbf{E} 169$ in colonies and their serial MIB subcultures grown at $37^{\circ}$

\begin{tabular}{ccccc} 
Colony & $\begin{array}{c}\text { In suspension of } \\
\text { whole colony } \\
\text { picked from MIA }\end{array}$ & \multicolumn{2}{c}{$\begin{array}{c}\text { In serial MIB subcultures } \\
\text { of colony suspension: }\end{array}$} \\
no. & 1st & 2nd & 3rd \\
1 & 7 & 4 & 6 & 5 \\
2 & 4 & 6 & 4 & 3 \\
3 & 3 & 4 & 7 & 9 \\
4 & 22 & 22 & 19 & 26 \\
5 & $<1$ & 7 & 9 & 14
\end{tabular}

* One hundred colonies screened for each estimate.

Frequency of $\mathrm{Tet}^{\mathrm{s}}$ variants in cultures grown at $37^{\circ}$. The frequency of Tet $^{\mathrm{B}}$ variants in five colonies of Staphylococcus aureus E 169 picked from MIA and in three serial MIB subcultures of the colony suspensions are shown in Table 2. The frequency of Tet $^{\mathrm{s}}$ variants attained during growth of four of the five colonies did not significantly alter during serial subculture. In the fifth colony, the frequency appeared to increase during the first subculture in $\mathrm{MIB}$, but then stabilized at about $10 \%$; the level around which the frequency in the four other series tended to cluster. These results suggested that the equilibrium frequency of Tet $^{\mathrm{S}}$ variants in cultures of $S$. aureus $\mathrm{E} 169$ grown at $37^{\circ}$ was about $10 \%$. Nevertheless, when logarithmically growing cultures of $S$. aureus $\mathrm{E} 169$ and one of its Tet $^{\mathbf{s}}$ variants isolated at $37^{\circ}$ were mixed to give a culture containing approximately $90 \%$ Tet $^{\mathrm{S}}$ cocci, there was no significant alteration in the frequency of $\mathrm{Tet}^{\mathrm{B}}$ cocci after about 14 population doublings of the artificially mixed culture at $37^{\circ}$.

\section{DISCUSSION}

The occurrence of a rather high number of Tet $^{\mathrm{B}}$ and Penase ${ }^{-}$colonies when the nominally Tet $^{\mathrm{B}}$ Penase $^{+}$Staphylococcus aureus E169 was plated-out might be regarded as evidence that, in spite of its mode of isolation, it was a mixed culture. Nevertheless, we are persuaded that the explanation is that the staphylococcus is 
inherently unstable with respect to tetracycline resistance and production of penicillinase.

The different rates of loss of tetracycline resistance and penicillinase-forming ability by Staphylococcus aureus $\mathrm{E} 169$ during growth at elevated temperature, with the consequent occurrence in 'terminal' populations of both Tet $^{\mathrm{R}}$ Penase $^{-}$and Tet $^{\mathrm{s}}$ Penase ${ }^{+}$in addition to Tet $^{\mathrm{B}}$ Penase ${ }^{-}$variants, shows that these two properties are lost independently. Furthermore, these losses at elevated temperature are clearly not environmentally induced phenotypic changes: the Tet $^{\mathrm{B}}$ and Penase ${ }^{-}$ variants are quite stable during repeated subculture at $37^{\circ}$, and the rates of reversion are less than $1 / 10^{9}$ cocci; indeed, no revertants have yet been observed.

Of the possible hypotheses which might be invoked to explain the phenomenon, several are highly improbable in the light of current evidence from other sources. For instance, heritable properties of staphylococci dependent on the presence of prophage have been reported by a number of workers (Blair \& Carr, 1961; Wahl \& Fouace, 1961; de Waart, Winkler \& Grootsen, 1962). However, since the Tet $^{\mathrm{s}}$ and Penase $^{-}$variants are immune to phage released by the parental strain, it does not seem possible that the observed alterations are associated with the loss of prophage. Neither does it appear possible that Tet $^{\mathbb{s}}$ variants present in the culture before exposure to elevated temperature selectively overgrow the Tet $^{\mathbb{R}}$ cocci. Such an overgrowth would require a doubling-time for the $\mathrm{Tet}^{\mathrm{B}}$ cocci of approximately $6.5 \mathrm{~min}$. between the third and fourth doublings in MIB at $44^{\circ}$, whereas the doubling times of both types were then about 27 min. (Fig. 5 and 6).

It is also unlikely that the changes are heat-induced mutations of the type described by Zamenhof \& Greer (1958). The speed with which the variants accumulate in the population in the absence of any demonstrable growth advantage would require an extraordinarily high mutation rate, particularly in the case of the Tet $^{\mathrm{R}}$ to $\mathrm{Tet}^{\mathrm{s}}$ variation. The stability of the numerous other 'marker' properties at $44^{\circ}$ also weighs somewhat against a mutational interpretation, although one could suppose that the Tet $^{\mathrm{R}}$ and Penase ${ }^{+}$loci were situated at heat-sensitive 'hot-spots' on the genome. But it would be necessary further to assume that such 'hot-spots' were unaffected by ultraviolet irradiation.

A more attractive hypothesis is that tetracycline resistance and penicillinaseforming ability are determined by autonomously-replicating cytoplasmic particles whose doubling rates are equal to the cell doubling rate at $37^{\circ}$, but whose replication is more or less suppressed at higher temperatures; under these conditions the particles would be diluted out until there was only one per cell, thereafter being inherited unilinearly in a 'one or none' manner (see Stocker, 1956). Thus with Staphylococcus aureus $\mathrm{E} 169$ growing in MIB, since the number of cocci per clump was approximately 2 at the time of transfer from $37^{\circ}$ to $44^{\circ}$ and 4 at the fifth population doubling at $44^{\circ}$, when about half of the clumps in the population were $\operatorname{Tet}^{\mathrm{R}}$, then at the time of transfer each cell would have contained about 4 Tet $^{\mathrm{R}}$-conferring particles. However, since there was no significant change in the state of aggregation of cocci beyond the fifth population doubling at $44^{\circ}$, the rate of disappearance of $\mathrm{Tet}^{\mathrm{R}}$ cocci during the same period suggests that the replication of the particles was not completely suppressed at this temperature and the estimate of four particles per cell is probably too high. The six doublings required at $43^{\circ}$ in medium NB-1 for half of the population to be Tet $^{\mathrm{R}}$ was probably due to the clumps of cocci being larger in this medium; 
indeed, medium NB-1 made from a second batch of 'Oxoid' Nutrient Broth granules even gave visible clumping of cultures grown at $37^{\circ}$. This distinction between MIB and medium NB-1, together with the inability of the latter to sustain the growth of $S$. aureus $\mathrm{E} 169$ at $44^{\circ}$, was presumably due to the differences in composition of the two media.

Recently, Jacob, Brenner \& Cuzin (1963) have described mutants of the sex factor in Escherichia coli; in the cytoplasmic state the mutant episomes were eliminated by growing the bacteria at $42^{\circ}$, but were temperature resistant when integrated with the chromosome. As yet, we have no evidence to suggest that particles conferring tetracycline resistance and penicillinase-forming ability on Staphylococcus aureus E 169 are episomes (Jacob \& Wollman, 1958) and consequently we have called them plasmids (Lederberg, 1952).

The insensitivity of the plasmids to acriflavine conflicts with previously reported properties of autonomously-replicating cytoplasmic particles conferring antibiotic resistance in Escherichia coli (Watanabe \& Fukasawa, 1961) and in Staphylococcus aureus (Mitsuhashi, Morimura, Kono \& Oshima, 1963). But Novick (1963) also concluded, from transductional and other genetic evidence, that penicillinase formation in $S$. aureus was controlled by an acridine-dye resistant plasmid.

The value of about $10 \%$ Tet $^{\mathbb{S}}$ variants in the predominantly Tet $^{\mathbf{R}}$ cultures derived from single colonies of Staphylococcus aureus E 169 suggested that this represented the equilibrium of the two types when growing at $37^{\circ}$, the random failure of a daughter cell to inherit any Tet $^{\mathrm{R}}$-conferring particle from its parent being counterbalanced by re-infection. However, the stability of artificially mixed cultures demonstrated that active reinfection did not occur under our experimental conditions. We are, therefore, at present unable to explain how populations which should seemingly be almost completely tetracycline sensitive actually remain dominantly tetracycline resistant.

We wish to thank Mr L. R. Rowett (Royal Perth Hospital) for performing the phage typing. This work was supported in part by a grant from the National Health and Medical Research Council of Australia.

\section{REFERENCES}

Adams, M. H. (1959). Bacteriophages. New York: Interscience Publishers, Inc.

Annear, D. I. (1962). Recoveries of bacteria after drying on cellulose fibres. A method for the routine preservation of bacteria. Aust. J. exp. Biol. med. Sci. 40, 1.

BARBER, M. (1949). The incidence of penicillin-sensitive variant colonies in penicillinaseproducing strains of Staphylococcus pyogenes. J. gen. Microbiol. 3, 274.

BARBer, M. \& KUPER, S. W. A. (1951). Identification of Staphylococcus pyogenes by the phosphatase reaction. J. Path. Bact. 63, 65.

Bisset, K. A. \& Hale, C. M. F. (1953). Complex cellular structure in bacteria. Exp. Cell. Res. 5, 449.

BlaIr, J. E. \& CARR, M. (1961). Lysogeny in staphylococci. J. Bact. 82, 984.

Blair, J. E. \& Williams, R. E. O. (1961). Phage typing of staphylococci. Bull. Wld Hlth Org. 24, z71.

Bondi, A., Konnblum, J. \& de Saint Phalle, M. (1953). Isolation of penicillin-susceptible mutants from penicillinase-producing strains of Micrococcus pyogenes. Proc. Soc. exp. Biol., N.Y. 83, 527. 
Borowski, J. (1963). Tendance naturelle des staphylocoques pénicillino-résistants a donner des mutants sensibles à la pénicilline. Relations de cette propriété avec l'origine des souches et leur sensibilité aux bactériophages. Ann. Inst. Pasteur, 104, 535.

ElEK, S. D. \& LEVy, E. (1954). The nature of discrepancies between haemolysins in culture filtrates and plate haemolysin patterns of staphylococci. J. Path. Bact. 68, 31.

Fairbrother, R. W., Parker, L. \& Eaton, B. R. (1954). The stability of penicillinaseproducing strains of Staphylococcus aureus. J. gen. Microbiol. 10, 309.

Foley, J. M. \& Perret, C. J. (1962). Screening bacterial colonies for penicillinase production. Nature, Lond. 195, 287.

Hutchison, J. G. P. (1962). Muller's phenomenon and its relationship to plasminogen activation and to blood constituents producing opacity in an agar gel. J. Path. Bact. 84, 289.

JACOB, F., Brenner, S. \& Cuzin, F. (1963). On the regulation of DNA replication in bacteria. Cold Spr. Harb. Symp. quant. Biol. $28,329$.

$\mathbf{J}_{\mathrm{ACOB}}$, F. \& Wollman, E. L. (1958). Les épisomes, éléments génétiques ajoutés. C.R. Acad. Sci., Paris, 247, 154.

Kantonowicz, 0 . (1951). Shaking apparatus for the aeration of bacterial cultures. J. gen. Microbiol. 5, 276.

Klemperer, R. \& Haughton, G. (1957). A medium for the rapid recognition of penicillinresistant coagulase-positive staphylococci. J. clin. Path. 10, 96.

Lederberg, J. (1952). Cell genetics and hereditary symbiosis. Physiol. Rev. 32, 403.

Mackie and McCartney's Handbook of Bacteriology (1960). 10th ed. Ed.by R. Cruickshank, p. 190. Edinburgh and London: Livingstone.

May, J. W. \& Houghton, R. H. (1964). A simple multipoint inoculator. Lab. Pract. (in the Press).

Mrtsuhashi, S., Morimura, M., Kono, K. \& Oshima, H. (1963). Elimination of drug resistance of Staphylococcus aureus by treatment with acriflavine. J. Bact. 86, 162.

Novick, R.P. (1963). Analysis by transduction of mutations affecting penicillinase formation in Staphylococcus aureus. J. gen. Microbiol. 33, 121.

Stocker, B. A. D. (1956). Abortive transduction of motility in salmonella; a nonreplicated gene transmitted through many generations to a single descendant. J. gen. Microbiol. 15, 575.

DE WAart, J., Winkler, K. C. \& Grootsen, CA. (1962). Lysogenic conversion in Staphylococci. Nature, Lond. 195, 407.

WAHL, R. \& Fouace, J. (1961). Mutations d'une souche de Staphylococcus aureus vers la résistance à l'érythromycine avec perte de prophages. Ann. Inst. Pasteur, 100, 553.

Watanabe, T. \& Fukasawa, T. (1961). Episome-mediated transfer of drug resistance in Enterobacteriaceae. II. Elimination of resistance factors with acridine dyes. J. Bact. $81,679$.

ZAMENHOF, S. \& GREER, S. (1958). Heat as an agent producing high frequency of mutations and unstable genes in Escherichia coli. Nature, Lond. 182, 611. 